\title{
Control Applications for Energy Saving in Marble Machining Process
}

\author{
S. M. Çınar, H. Çimen, and A. Zengin
}

\begin{abstract}
Energy consumption is the main cost item in the marble cutting process by using segmented circular sawblade. Therefore, there are many benefits to take measures for reducing the energy consumption. The aim of this study is to reduce electricity consumption in marble cutting process by using control methods. In the study, cutting experiments were performed with a fully computer controlled test rig for three natural rocks (Burdur beige and Usak green marbles and Afyon travertine). The experiments were carried out on two modes (manual and automatic). In the experiments, travel speed is kept fixed in manual mode as usual in industry. In the experiments performed on automatic mode, travel speed is controlled by a controller embedded closed control loop during the cutting process. In addition other machine parameters such as sawblade rotation speed, cutting depth, flowing speed of cooling water are kept fixed in all experiments. In designed control systems, floating and PID controllers are used to control travel speed. Obtained results are showed that, if the travel speed is controlled during cutting process, energy saving can be provided in both of two controllers for all of three rocks.
\end{abstract}

Index Terms - Energy saving, marble cutting, applied control, floating and PID controller.

\section{INTRODUCTION}

Afyon is one of the most important marble supplier cities of the world and Turkey with its plenty of marble mines and factories. For separating the block marbles taken from mine to plaques, block cutting machines segmented diamond circular sawblade are used.

There exist many parameters effecting the cutting operation in circular sawblade cutting process. These are separated two parts; first one is machine parameters (sawblade rotation speed, travel speed, cutting depth, flowing speed of cooling water, cutting mode 'down or up-cutting', metallurgic and mechanic features of diamond sockets, sawblade thickness), second one is rock parameters (mineralogical and physical-mechanical features) [1, 2, 6-8]. Many studies have been realized to examine the effects of the said parameters [3-5]. Specific energy is defined as energy consumed per unit volume and it can be used to monitor efficiency of marble cutting process. The sawblade rotation and travel speeds have significant effects on specific energy. In studies, it is observed that the travel speed effect is more than the sawblade rotation speed effect $[4,7]$.

In industry, block cutting machines called as

Manuscript received July 19, 2012, revised September 10, 2012.

Said Mahmut Çınar and Hasan Çimen are with the Electrical Engineering Dept., Afyon Kocatepe University, Afyon/Turkey (e-mail: smcinar@gmail.com; hcimen@aku.edu.tr).

Ahmet Zengin is with the Computer Engineering Dept, Sakarya University, 54187 Sakarya/ Turkey (e-mail: azengin@sakarya.edu.tr). stripper-trimmer (ST) are widely used for separating block marble to plaques. In the ST machines, sawblade rotation speed is usually adjusted with wheel-belt systems and it is fixed during cutting process. Travel speed is changed by machine operator and it is commonly held on fixed value. However, marble is not homogenous material and it can contain different hardness regions. Because of these fixed parameters, efficiency decreases in cutting process. For adjusting sawblade rotation speed, motor drivers were recently used in ST machines, but drivers are not widely used. On the other hand, for changing travel speed, drivers are nearly used in whole of ST machines.

In the circular cutting process, if travel speed is controlled by a controller embedded in closed control loop, energy saving is possible. In a study travel speed has been controlled by floating controller and $10 \%$ energy saving is carried out [8]. This study is showed that if travel speed is controlled by advanced controllers such as PID and fuzzy logic, more energy saving can be obtained.

In presented study, we examine floating and PID controllers embedded in closed control loop. Three natural rocks (Burdur beige marble, Usak green marble and Afyon travertine) are used as work piece for sawing experiments. Cutting experiments were performed with a fully computer controlled test rig designed just as ST machine [4, 6]. An interface which provides control of the test rig was designed with National Instrument (NI) LabVIEW programming language which is widely used for academic and industrial applications [9]. In addition NI PID toolset was used for designing PID controller. In below, firstly, control loop and controllers are presented. Then, results obtained from experiments are given and discussed.

\section{CONTROL LOOP AND CONTROLLERS}

In the marble processing industry, the specific energy can be used to monitor efficiency of cutting process and for predicting required energy. Sawblade rotation speed, travel speed, cutting depth, flowing speed of cooling water, cutting mod, metallurgic and mechanic features of diamond sockets, sawblade thickness, and marble features are directly connected with the specific energy. Travel speed effect is the most within these parameters [4, 7].

There is adverse proportion between travel speed and specific energy. In Fig. 1, an experimental result which is performed for Usak green marble is seen. This experiment is started with $0,7 \mathrm{~m} / \mathrm{min}$. travel speed and after the sawblade entering completely within the marble, travel speed is gradually increased. With increase in travel speed, decreasing is showed in specific energy. The specific energy 
arrives to $0.9 \mathrm{Ws} / \mathrm{mm}^{3}$ value for $1.4 \mathrm{~m} / \mathrm{min}$. travel speed. However, though travel speed is increased to $1.5 \mathrm{~m} / \mathrm{min}$., specific energy is nearly fixed to $0.9 \mathrm{Ws} / \mathrm{mm}^{3}$ value. If travel speed is continued to be increased, increasing trend is expected in specific energy. This extreme point is called optimum specific energy.

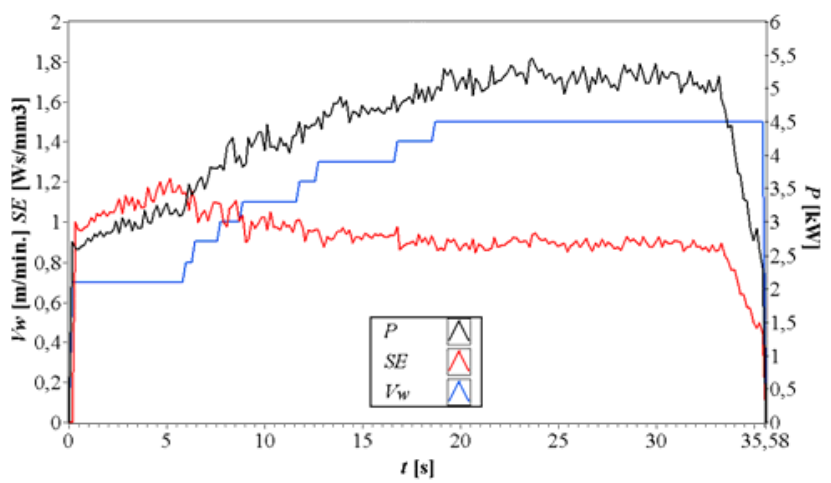

Fig. 1. Relationship between travel speed and specific energy

In ST machines, travel speed is commonly adjusted by machine operator and it is held on fixed value. However, marble is not homogenous material and it can contain different hardness regions. Because of these fixed parameters, energy efficiency decreases in cutting process. If the optimum specific energy is determined and travel speed is controlled as keeping this specific energy, energy efficiency can be obtained in marble cutting process. This can be provided as travel speed is controlled by controller. In this study, by travel speed is controlled on closed loop, energy consumption was tried to reduce.

In control loop, single input single output (SISO) and multi input single output (MISO) controllers were used. In this study, performance of MISO floating and SISO PID controllers are tested according to experiment performed on fixed travel speed. In below, architecture of floating and PID controllers are presented.

\section{A. Floating Controller}

This is a controller between two positions (On-Off) and proportional controllers and it is called three positions or floating controller. In this controller, controlled variable floats until it is settled in between up and down limits. Floating controller which is designed in this study is seen in Fig. 2. With increasing or decreasing the travel speed, principle of the floating controller tries to settle in reference specific energy.

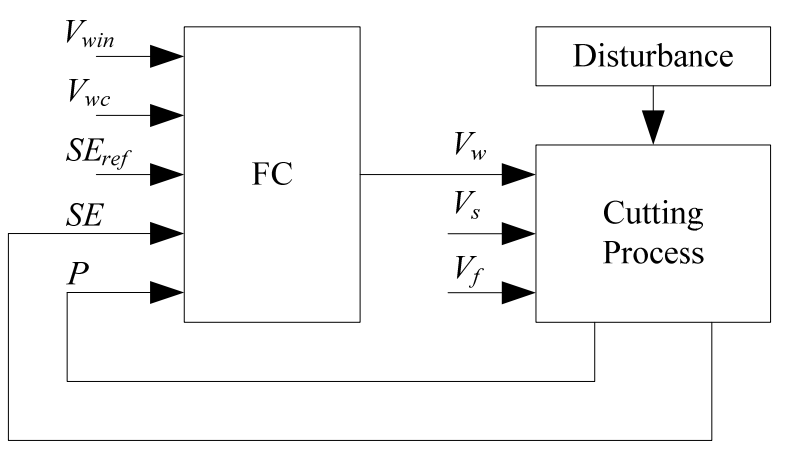

Fig. 2. Control loop with floating controller
In floating controller, before experiment is started, required or reference specific energy $\left(S E_{r e f}\right)$ changing value of travel speed $\left(V_{w c}\right)$ and initial value of travel speed $\left(V_{w i n}\right)$ are set. Where changing value of travel speed determines to speed of controller and it is very important controller parameter. If changing value of travel speed is small, reaction time decreases (conservative controller), else it is large, reaction time increases (aggressive controller). In cutting experiments, changing value of travel is determined by trial and error and it examined for four different values.

\section{B. PID Controller}

Today, PID controller is by far the most common control algorithm in industrial application [11]. PID control algorithm is commonly used to control or observe heating/cooling, fluid level, flow and pressure control processes. In PID controller, process variable $(P V)$ and reference or set point (SP) must be set (Fig. 3). Process variable is process parameter such as temperature, pressure or flow rate which is expected to control.

$$
e=S P-P V
$$

With subtracting set point and process variable, PID controller is made an error $(e)$ signal. Error signal is given in "(1)".

$$
u(t)=K_{c}\left(e+\frac{1}{T_{i}} \int_{0}^{t} e \cdot d t+T_{d} \frac{d e}{d t}\right)
$$

In this study, PID controller calculates a control signal according to Eq. "(2)". Where; $K_{c}$ is controller gain. $T_{i}$ and $T_{d}$ are sequentially integral and derivative time constants in minutes. The integral and the derivative time constants are also called as reset and rate time [10]. In below, Eq. "(3)", "(4)" and "(5)" represent sequentially proportional, integral and derivative action.

$$
\begin{gathered}
u_{P}(t)=K_{c} e \\
u_{I}(t)=\frac{K_{c}}{T_{i}} \int_{0}^{t} e d t \\
u_{D}(t)=K_{c} T_{d} \frac{d e}{d t}
\end{gathered}
$$

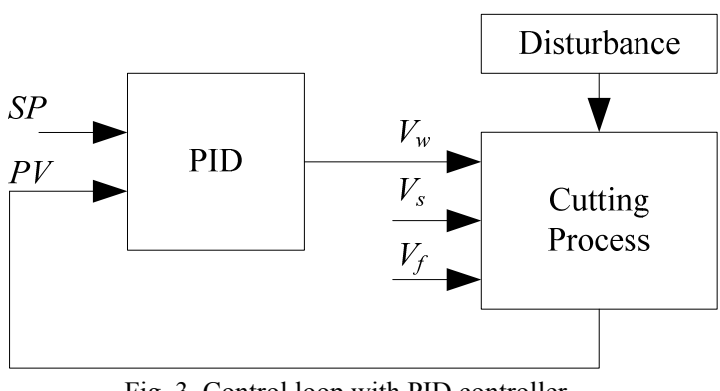

Fig. 3. Control loop with PID controller

There are three PID controller parameters $\left(K_{c}, T_{i}\right.$ and $\left.T_{d}\right)$ except for process variable and the set point. These 
parameters are described behaviour of controller and they must be set according to rock type. For example, when a rock which contains different hardness regions is cut, fluctuations are seen in sawblade motor active power curve. In order to remove these fluctuations or oscillations, derivative or rate time $\left(T_{d}\right)$ must be adjusted. Moreover, when a rock which has homogeneous structure is cut, there are almost no oscillations in sawblade motor active power curve. Where, the controller can create a steady state error and this error is destroyed with integral action. In order to remove this error integral or reset time $\left(T_{i}\right)$ must be adjusted. In equation "(2)", however, integral and derivative time constants are multiplied with controller gain. So, when these time constants are changed, the controller gain $\left(K_{c}\right)$ should be adjusted. The controller gain is most important parameter for setting rise time and overshoot.

\section{EXPERIMENTAL RESULTS}

In cutting process, there are many parameters effecting energy consumption and each of these parameters is research subject. Because parameters except for travel speed are out of this study, these parameters are fixed. Fixed parameters are sequentially; sawblade rotation speed $V_{s}=1500 \mathrm{rpm}$, cutting dept $d=50 \mathrm{~mm}$, flowing speed of cooling water $V_{f}=101 / \mathrm{min}$. and sawblade produced by UNIMAS having 24 diamond segments. Besides cutting mode is important parameter in cutting process. In the circular cutting process, there are two cutting mode such as up-cutting and down-cutting. In this study, as it is more suitable for cutting natural rocks, down-cutting mode is selected.

In this study, cutting experiments were performed for three natural rocks (Burdur beige and Usak green marbles and Afyon travertine). In cutting experiments, work pieces having a length $900 \mathrm{~mm}$ and $70 \mathrm{~mm}$ and $200 \mathrm{~mm}$ section are used. For each rock, one cutting experiment is performed in fixed travel speed (manual cutting mode) for determining parameters of floating and PID controllers. In manual cutting mode, the motor has been operated $10 \%$ below its nominal power for secure cutting process. Specific energy values obtained for each rock are followed; $1,308 \mathrm{Ws} / \mathrm{mm}^{3}$ for Burdur beige marble in $1.1 \mathrm{~m} / \mathrm{min}$., $1,039 \mathrm{Ws} / \mathrm{mm}^{3}$ for Usak green marble in $1.4 \mathrm{~m} / \mathrm{min}$., $0,811 \mathrm{Ws} / \mathrm{mm}^{3}$ for Afyon travertine in $1.1 \mathrm{~m} / \mathrm{min}$. In bellow, experimental results are seen for Burdur beige and Usak green marbles and Afyon travertine (Fig. 4).

Although their magnitudes are different, sawblade motor power and specific energy curves have similar characteristic in fixed travel speed. Burdur beige marble is more hard rock with its $1.308 \mathrm{Ws} / \mathrm{mm}^{3}$ specific energy. On the other hand Afyon travertine more soft rock with its $0,811 \mathrm{Ws} / \mathrm{mm}^{3}$ specific energy. When power and specific energy curves are examined, they are seen that there is an oscillation for Burdur beige marble and Afyon travertine but Usak green marble is nearly fixed. This means that Burdur beige marble and Afyon travertine are not homogenous rocks having different hardness regions and Usak green marble is homogenous rock. It is thought that, when these rocks' features are taken into account, energy saving can be provided with arranging travel speed.
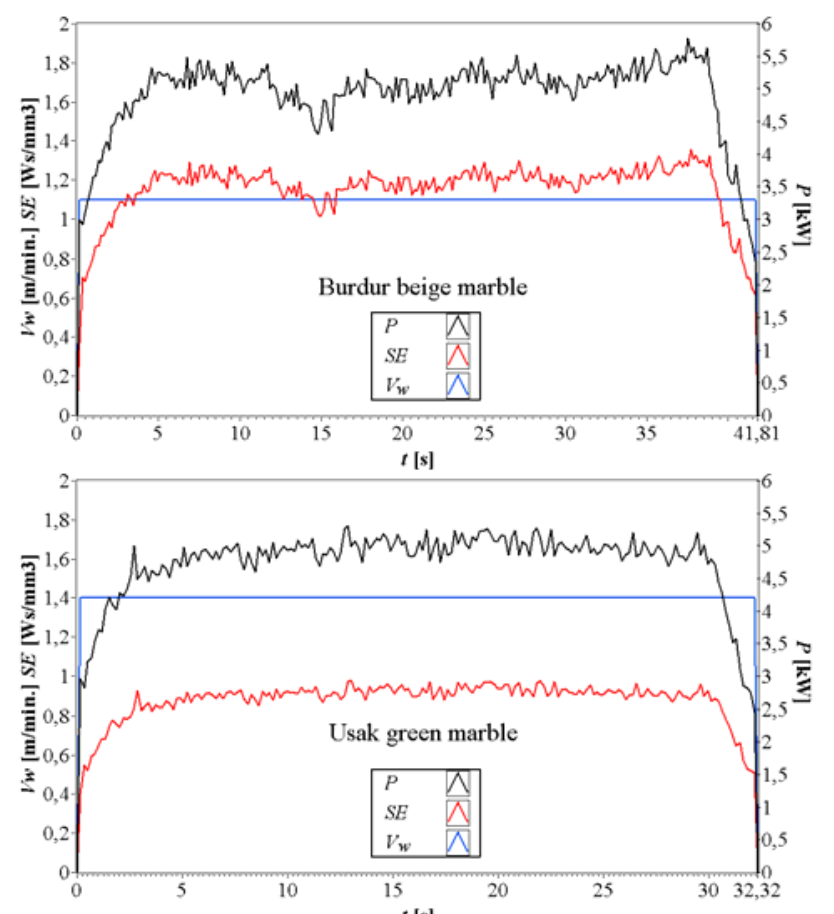

$t[\mathrm{~s}]$

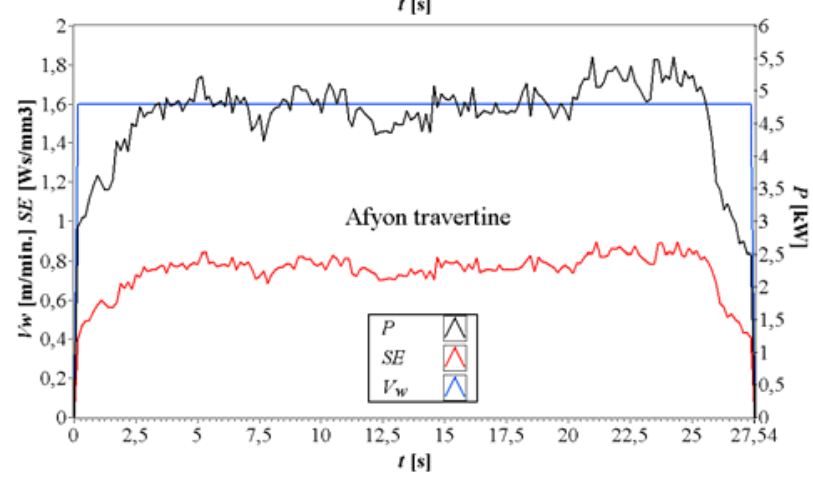

Fig. 4. Experimental results for fixed travel speed

In below, experimental results performed with floating and PID control methods are presented. Than effecting control methods in specific energy and energy saving amount achieved in each control methods are given.

\section{A. Results for Floating Controller}

Parameters of floating controller are determined to experimental results achieved manual cutting in fixed travel speed for each rock. Controller parameters such as reference specific energy $\left(S E_{r e f}\right)$, changing value of travel speed $\left(V_{w c}\right)$ and initial value of travel speed $\left(V_{\text {win }}\right)$ are followed for Burdur beige and Usak green marbles and Afyon travertine (Table I).

\begin{tabular}{lcc} 
TABLE I: PARAMETERS OF FLOATING CONTROLLER AND SE VALUE & $\boldsymbol{V}_{\boldsymbol{w c}}[\mathrm{m} / \mathrm{dk}]$ & $\boldsymbol{S E}\left[\mathrm{Ws} / \mathrm{mm}^{3}\right]$ \\
\hline \hline Burdur beige marble & 0,02 & 1,26 \\
& 0,03 & 1,217 \\
$\boldsymbol{S E}_{\text {ref }}=0,95 \mathrm{Ws} / \mathrm{mm}^{3}$ & 0,04 & 1,199 \\
$\boldsymbol{V}_{\text {win }}=1,1 \mathrm{~m} / \mathrm{dk}$ & $\mathbf{0 , 0 5}$ & $\mathbf{1 , 1 4 8}$ \\
\hline Usak green marble & 0,02 & 0,987 \\
& 0,03 & 0,967 \\
$\boldsymbol{S} \boldsymbol{E}_{\text {ref }}=0,8 \mathrm{Ws} / \mathrm{mm}^{3}$ & 0,04 & 0,966 \\
$\boldsymbol{V}_{\text {win }}=1,4 \mathrm{~m} / \mathrm{dk}$ & $\mathbf{0 , 0 5}$ & $\mathbf{0 , 9 4 2}$ \\
\hline \multirow{2}{*}{ Afyon travertine } & 0,02 & 0,785 \\
& 0,03 & 0,776 \\
$\boldsymbol{S} \boldsymbol{E}_{\text {ref }}=0,7 \mathrm{Ws} / \mathrm{mm}^{3}$ & $\mathbf{0 , 0 4}$ & $\mathbf{0 , 7 6 3}$ \\
$\boldsymbol{V}_{\text {win }}=1,6 \mathrm{~m} / \mathrm{dk}$ & 0,05 & 0,766 \\
\hline \hline
\end{tabular}


In addition to four values $(0,02-0,03-0,04-0,05 \mathrm{~m} / \mathrm{min}$.) are determined for changing value of travel speed used to adjust controller performance in all of rocks. In Table 1, specific energy values are given for each changing value of travel speed.
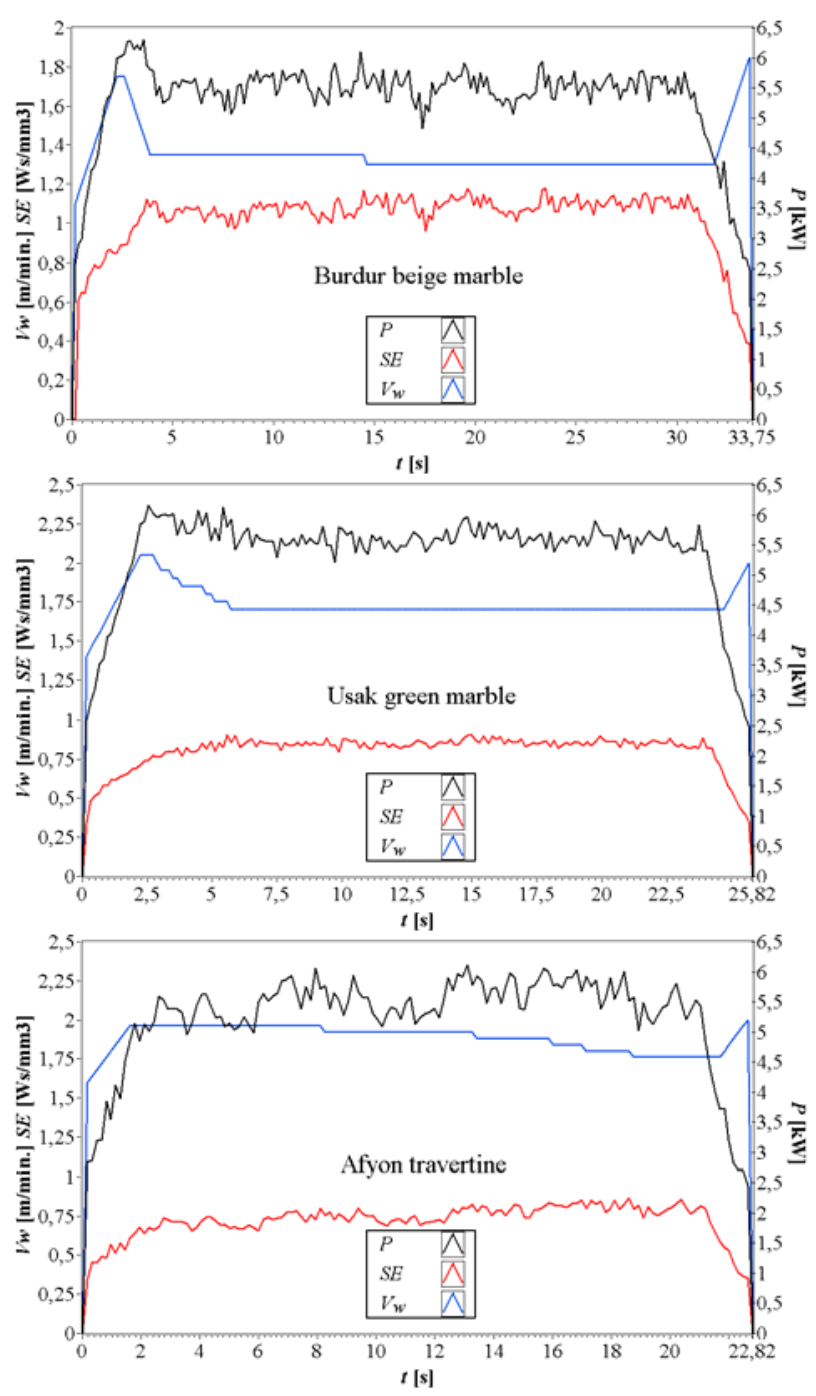

Fig. 5. Experimental results for floating controller

The best three result obtained minimum specific energy within 12 experiments is given in Fig. 5. In these cutting experiments, minimum specific energy values are achieved sequentially in $V_{w c}=0,05 \mathrm{~m} / \mathrm{min}$. for Burdur beige and Usak green marble, in $V_{w c}=0,04 \mathrm{~m} / \mathrm{min}$. for Afyon travertine (Table 1). Obtained specific energy values are $1,148 \mathrm{Ws} / \mathrm{mm}^{3}$ for Burdur beige marble, $0,942 \mathrm{Ws} / \mathrm{mm}^{3}$ for Usak green marble and $0,763 \mathrm{Ws} / \mathrm{mm}^{3}$ for Afyon travertine. In floating controller, controller reaction time decreases for small changing value of travel speed and it is increases for big changing value of travel speed. In Afyon travertine, however, it is seen that cutting efficiency decreases for big changing value of travel speed.

\section{B. Results for PID Controller}

Reference power or set point $\left(P_{r e f}\right)$ parameter is set to sawblade nominal power (5500W) in PID controller. Other PID parameters; controller gain $K_{c}$, integral time $T_{i}$ and derivative time $T_{d}$ are tried to be determined to rock properties.
Since Burdur beige marble and Afyon travertine comprises different hardness regions, oscillations are seen in sawblade power curve. In order to remove these oscillations, derivative time must be adjusted. As Usak green marble has homogenous structure, PID controller creates a steady state error. For removing this error, integral time must be adjusted. Because derivative and integral time constants are multiplied with controller gain, all parameters are adjusted together.

TABLE II: PID PARAMETERS AND SE VALUES

\begin{tabular}{ccccc}
\hline \hline & $\boldsymbol{K}_{\boldsymbol{c}}$ & $\boldsymbol{T}_{\boldsymbol{i}}[\mathrm{min}]$. & $\boldsymbol{T}_{\boldsymbol{d}}[\mathrm{min}]$. & $\boldsymbol{S E}\left[\mathrm{Ws} / \mathrm{mm}^{3}\right]$ \\
\hline & 1 & 0,06 & $20 \cdot 10^{-6}$ & 1,282 \\
Burdur beige marble & 1 & 0,05 & $20 \cdot 10^{-6}$ & 1,179 \\
& 1 & 0,06 & $15 \cdot 10^{-6}$ & 1,165 \\
& $\mathbf{1}$ & $\mathbf{0 , 0 4}$ & $\mathbf{2 0} \cdot \mathbf{1 0}^{-6}$ & $\mathbf{1 , 0 7 7}$ \\
\hline Usak & 0,9 & 0,03 & $20 \cdot 10^{-6}$ & 0,978 \\
green marble & 1 & 0,04 & $10 \cdot 10^{-6}$ & 0,956 \\
& 1 & 0,04 & $15 \cdot 10^{-6}$ & 0,954 \\
Afyon & $\mathbf{1}$ & $\mathbf{0 , 0 4}$ & $\mathbf{5 \cdot 1 0 ^ { - 6 }}$ & $\mathbf{0 , 9 2 2}$ \\
travertine & 1 & 0,06 & $20 \cdot 10^{-6}$ & 0,781 \\
& 1 & 0,05 & $30 \cdot 10^{-6}$ & 0,743 \\
& 0,9 & 0,04 & $15 \cdot 10^{-6}$ & 0,729 \\
& $\mathbf{0 , 8}$ & $\mathbf{0 , 0 5}$ & $\mathbf{3 0} \cdot \mathbf{1 0}^{-6}$ & $\mathbf{0 , 7 1 7}$ \\
\hline \hline
\end{tabular}

Selected PID controller parameters are given in Table II. The best PID parameters are manually determined via try and error method. In Table 2, minimum specific energy values are given with bold font.
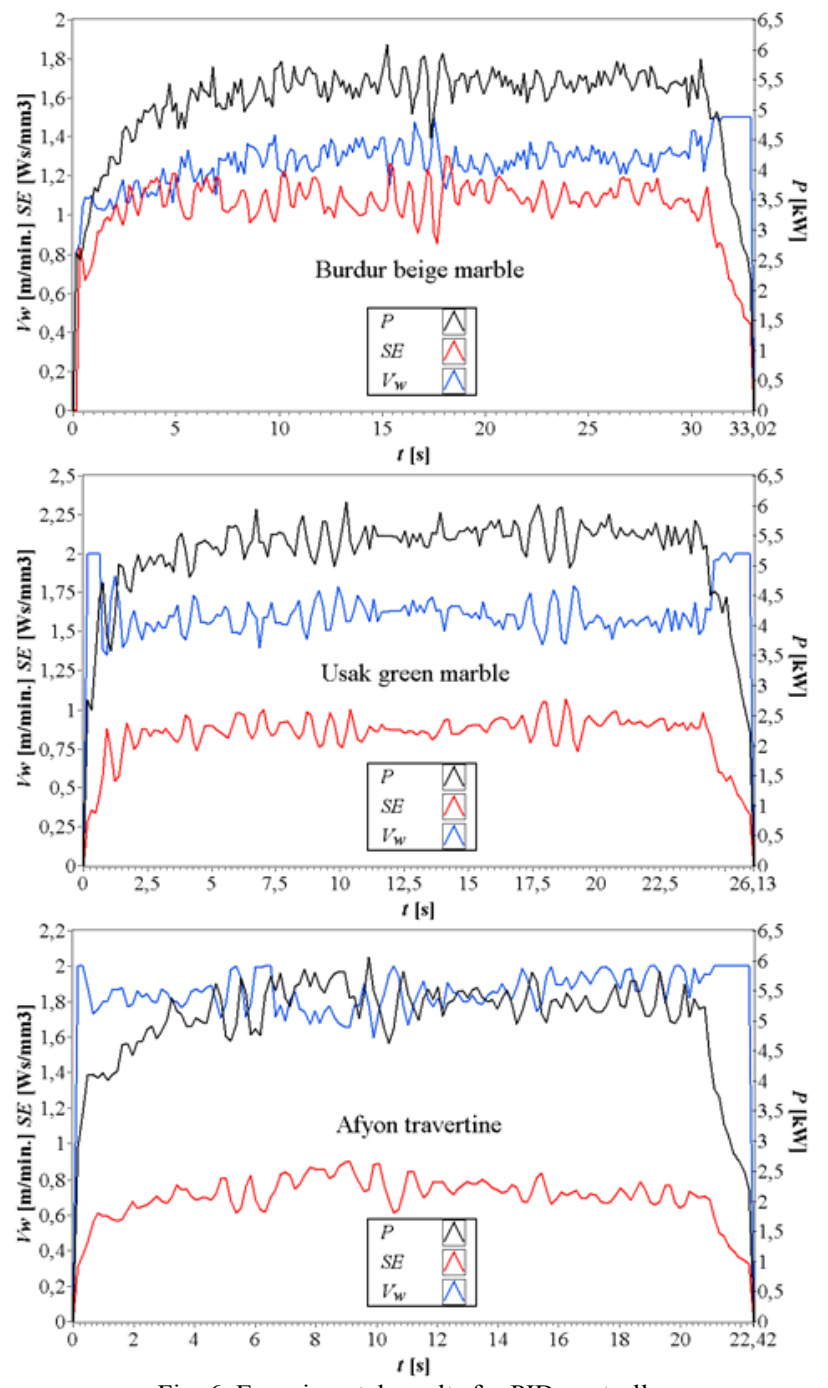

Fig. 6. Experimental results for PID controller 
The best three result obtained minimum specific energy are seen for Burdur beige and Usak green marbles and Afyon travertine in Fig. 6. Obtained specific energy values are $1,077 \mathrm{Ws} / \mathrm{mm}^{3}$ for Burdur beige marble, $0,922 \mathrm{Ws} / \mathrm{mm}^{3}$ for Usak green marble and $0,717 \mathrm{Ws} / \mathrm{mm}^{3}$ for Afyon travertine.

\section{Control Methods Effecting Specific Energy}

Minimum specific energy values achieved cutting experiments for each control method are examined in this section. In below, these values are given for manual, floating and PID control methods (Fig. 7). In Fig. 7, specific energy values achieved in manual experiments are given in first column of table. Specific energy is reduced in all of experiments arranged travel speed with control methods.

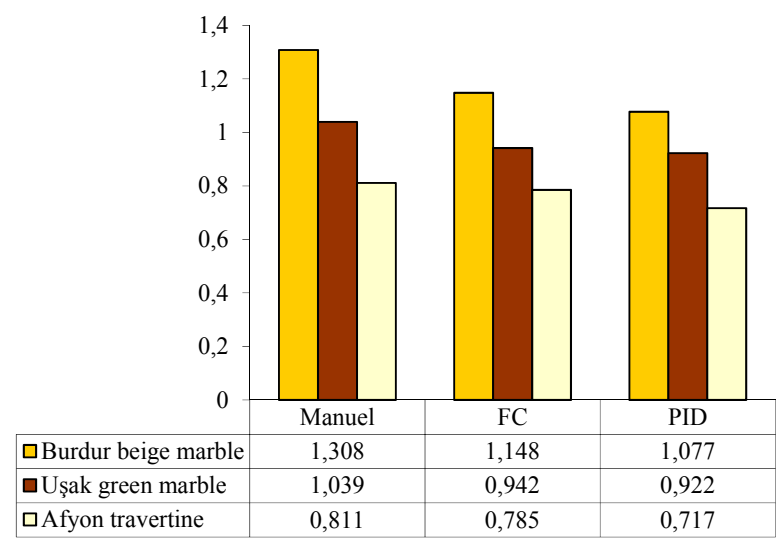

Fig. 7. Specific energy values for control methods

Energy saving values is given as percentage in Fig. 8. It is seen that the best saving is obtained in PID controller. Maximum energy saving is $17,66 \%$ and it is achieved in Burdur beige marble.

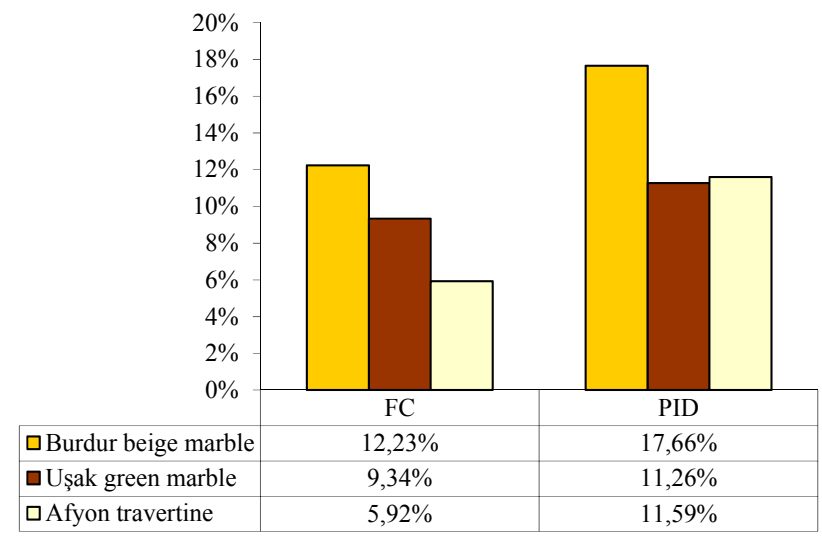

Fig. 8. Saving amount for control methods

\section{CONCLUSION}

In this study, with arranged travel speed, energy consumed in circular cutting process tried to reduce. Floating and PID controllers were used in control loop which is set for arranging travel speed. Cutting experiments were performed for three natural rocks (Burdur beige and Usak green marbles and Afyon travertine). Results achieved in cutting experiments are given below;

-In designed controllers, energy saving is partly provided. The best result is carried out in PID controller.
-In floating controller, with increasing or decreasing changing value of travel speed, reaction time of controller can be changed, but settling time of controller is very large. So, this reduces energy efficiency.

-PID controller which is widely used in industry is operated with power feedback. So, best results are achieved with PID controller.

-In this study, $17,66 \%$ maximum energy efficiency is carried out with PID controller for Burdur beige marble. In PID controller, obtained energy efficiency is about $11 \%$ for Afyon travertine and Usak green marble. Reason of obtaining more energy efficiency in Burdur beige marble contains different hardness regions in this marble. When heterogeneous rocks such as Burdur beige marble are cut with fixed travel speed, cutting efficiency reduces. However, if travel speed is arranged considering content of cut region, cutting efficiency raises.

-Because PID parameters must be determined to rock properties, using PID controller is not effective for marble machining process. So, expert systems such as fuzzy logic will so convenient for this process.

\section{ACKNOWLEDGEMENT}

This study was sponsored by a project (106E164).of The Scientific \& Technological Research Council of Turkey.

\section{REFERENCES}

[1] I. S. Büyüksağiş, and R. M. Goktan, "Investigation of Marble Machining Performance Using an Instrumented Block-cutter", Journal of Materials Processing Technology, vol. 169i pp. 258-262, 2005.

[2] X. P. Xu, Y. Li, and S. Malkin, "Forces and Energy in Circular Sawing and Grinding of Granite", Journal of Manufacturing Science and Engineering, vol. 123, pp. 13-22, 2001.

[3] I. S. Büyüksağiș, "Analysis of circular marble sawing using a block cutter", Ph.D. dissertation, Dept. Mining Eng. Osmangazi Univ., Eskișehir, 1998.

[4] S. M. Çınar, "Optimization of electric energy consumption in marble cutting machines", M.S. thesis, Electrical Educ., Afyon Kocatepe Univ., Afyonkarahisar, 2007.

[5] A. Ersoy and U. Atıc1, "Performance characteristics of circular diamond saws in cutting different types of rocks", Diamond and Related Materials, vol. 13, pp. 22-37, 2004.

[6] H. Çimen, S. M. Cinar, and M. Nartkaya, "The Development of Software and Hardware for Marble Cutting Tests", in Proc. 2nd WSEAS Int. Conf on Computer Engineering and Applications (CEA'08), Jan. 2008, pp.244-249.

[7] H. Çimen, and S.M. Çınar, "Energy consumption analysis in marble cutting processing", in Proc. International Symposium on Sustainable Development (ISSD2009), Jun 2009, pp. 1-6.

[8] H. Çimen, S.M. Çınar, M. Nartkaya, and İ. Yabanova, "Energy Efficiency in Natural Stone Cutting Process", in Proc. IEEE Conference on Global Sustainable Energy Infrastructure (IEEE Energy 2030), Nov. 2008, pp. 1-6.

[9] J. H. Horng, "Hybrid MATLAB and LabVIEW with neural network to implement a SCADA system of AC servo motor", Advances in Engineering Software, vol. 39, pp. 149-155, 2008.

[10] NI LabVIEW, PID and Fuzzy Logic Toolkit User Manual, Austin-Texas, 2009.

[11] K. Astrom, T. Hagglund, PID Controllers: theory, design and tuning, Research Triangle Park, ISA Press, 1995.

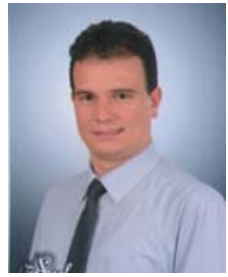

Said Mahmut Çınar is an Assist. Professor in Electrical Engineering Dept. at the Afyon Kocatepe University. He completed his B.S. in Electrical Engineering at the Kocaeli University in 2003. He got his M.S. in the Electrical Education Department at the University of Afyon Kocatepe in 2007. He received his Ph.D. in Electronic and Computer Education Department at Sakarya University, Turkey in 2011. 
His work focuses on applications of Energy efficiency, Data acquisition, Automation technologies, Renewable energy resources, Power Electronics, and microcontroller based embedded design.

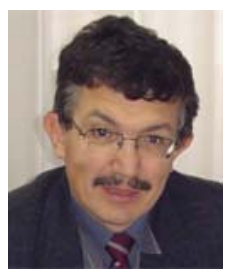

Hasan Çimen is a Professor in the Department of Electrical-Electronic Engineering Dept. at the Afyon Kocatepe University. He completed his B.S. in Electrical Education at the University of Marmara in 1985. He got his M.S. in Electrics at Marmara University in 1988. He received his Ph.D. in Electrical Engineering at Sussex University, England in 1998. His work focuses on applications of Rubust control, and Energy.

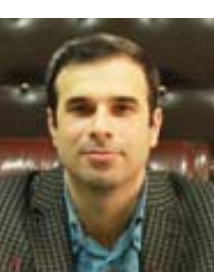

Ahmet Zengin is an Assoc. Professor in the Department of Electrical-Electronic Engineering Dept. at the Sakarya University. He completed his B.S. in Department of Electrical-Electronic Engineering Dept. at the Sakarya University in 1997. He got his M.S. in Electrical-Electronic Engineering Dept. at the Sakarya University in 1999. He received his Ph.D. in Electrical-Electronic Engineering Dept. at the Sakarya University in 2004. His work focuses on applications of Computer and Communcation Network, and Information Systems. 